\title{
DENSITIES OF LOGGERHEAD SHRIKE ON STUDY BLOCKS IN SOUTHEASTERN ALBERTA INVENTORIED IN BOTH 1993 AND 1996
}

RONALD R. BJORGE, Alberta Environmental Protection, Natural Resources Service, \#404, 4911-51 Street, Red Deer, Alberta T4N 6V4, and HENK P.L. KILIAAN, Canadian Wildlife Service, Suite 200, 4999-98 Avenue, Edmonton, Alberta T6B 2X3

Many of the world's 30 species of shrikes (Laniidae) are considered to be declining. ${ }^{9}$ Loggerhead Shrike (Lanius ludovicianus) populations are of concern throughout much of their range. In eastern Canada, the Loggerhead Shrike is classified as endangered and the population west of Winnipeg as threatened. ${ }^{4}$ Populations declined significantly from the 1950 s to the $1980 \mathrm{~s},{ }^{2,5,7}$ but Price and Droege (1995) have suggested that Loggerhead Shrike numbers have been more stable over the past decade. Because population trends can vary substantially from one region to another, it is important to monitor Loggerhead Shrike populations at the regional level.

In 1993, the Alberta population of Loggerhead Shrike in southeastern Alberta was estimated ${ }^{1}$ by thorough checks of randomly selected study blocks within $23,600 \mathrm{~km}^{2}$ of core shrike habitat ${ }^{8}$ in the northern portion of the mixed grass ecoregion. During 1996, H. Kiliaan reinventoried 12 of the 26 study blocks that were first censused in 1993. We report the results of the 1993 and 1996 censuses.

\section{Methods}

Field techniques in 1996 were similar to those used in $1993 .{ }^{1}$ Briefly, $6.4 \mathrm{~km} \times 6.4 \mathrm{~km}$ study blocks were intensively searched between 15 June and 7 July. All areas supporting woody vegetation were surveyed using a combination of truck, all-terrain vehicle and foot travel. Study blocks were selected randomly for the 1993 census. Study blocks inventoried in 1996 were representative of the range of shrike densities recorded in the 1993 inventory. Independent observations of shrikes within $400 \mathrm{~m}$ of one another were considered to be either the same pair (2 birds observed) or the same individual, unless additional observations or information (behavioural interactions or the presence of a second nest) indicated otherwise. Because repeat visits to nine territories (six in 1992 and three in 1993) where single birds had been observed originally, revealed two adults with eggs or young in all cases, each single shrike more than $400 \mathrm{~m}$ from any other was regarded as an indicated pair. Also, Collister (pers. comm.) concluded that there were very few unpaired adults on his intensive study area ${ }^{3}$ in southeastern Alberta. The current study area was located in the northern portion of the mixed-grass ecoregion of Alberta and has been described previously. ${ }^{1}$ 


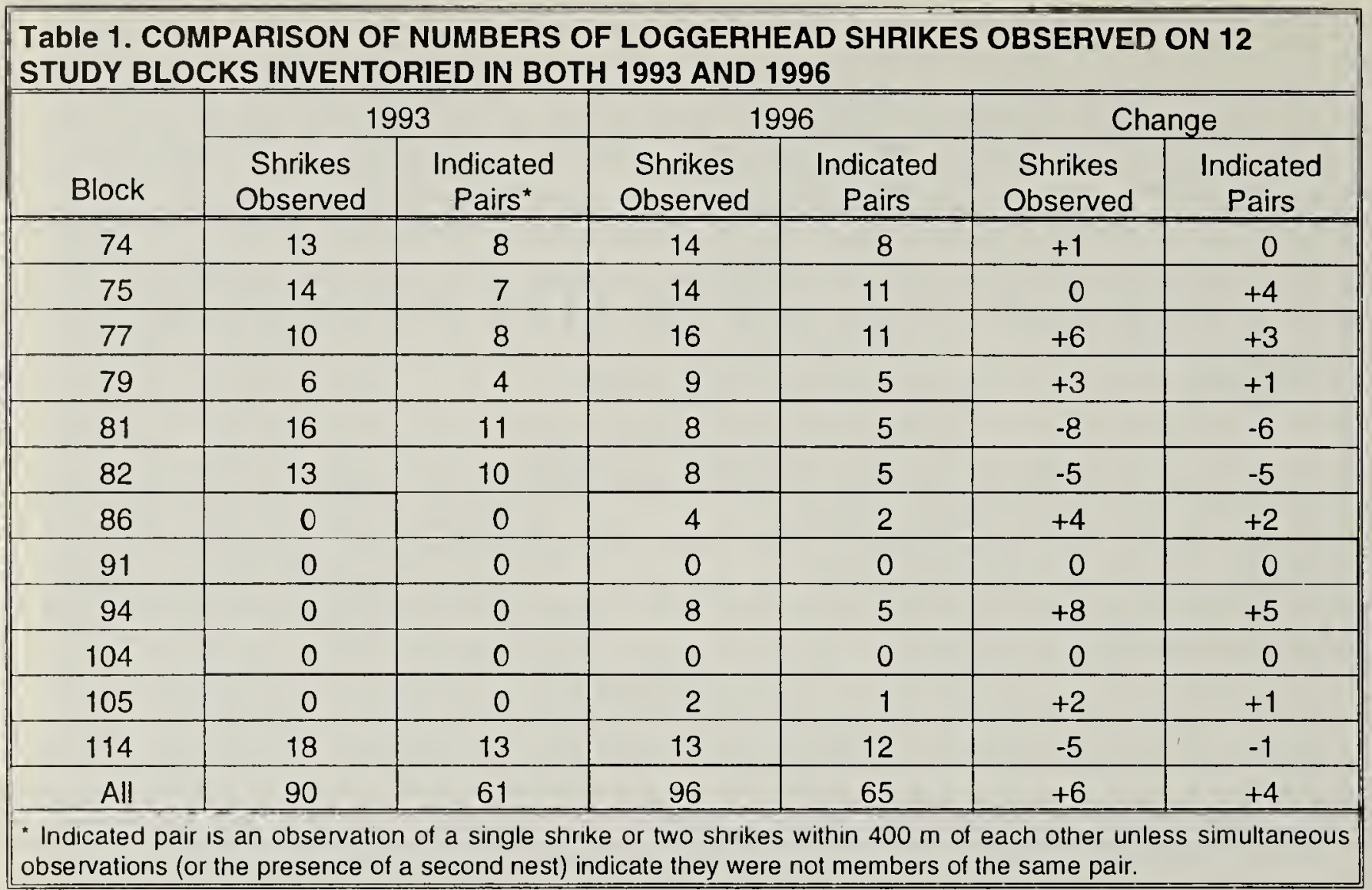

\section{Results}

Ninety-six shrikes and 65 indicated pairs were observed on the 12 study blocks censused in 1996 (Table 1). In 1993, ninety shrikes and 61 indicated pairs were observed on these same study plots. The mean number of indicated pairs per study plot in $1996(5.41 \pm 1.24)$ was not significantly different from the corresponding mean $(5.08 \pm 1.44)$ from the 1993 census. In 1996, the ratio of observed pairs to indicated pairs was 27:65, quite similar to the corresponding ratio from the 1993 census (24:61).

Indicated pair numbers were quite stable for 7 of the 12 study blocks. Indicated pair numbers changed by 2 or less for these blocks. Two study blocks supported substantially fewer (-5 and -6$)$ indicated pairs in 1996, and three study blocks supported substantially more $(+3,+4$ and +5$)$ indicated pairs in 1996 than in 1993.

\section{Discussion}

Our results concur with the suggestion that shrike numbers have been relatively stable in western Canada over the past four or five years. ${ }^{6}$ There was little change in numbers of shrikes or indicated pairs in our study. The slight increases observed are difficult to interpret. We intentionally selected study plots that represented the range of shrike numbers encountered during the 1993 census, including five study plots that supported no shrikes during that census. As it was impossible for shrike (or indicated pair) numbers to decline on these five study plots, our comparison may be biased toward showing an increase. If these five study plots are eliminated from the comparison the total numbers of shrikes and indicated pairs decreased by eight birds and four pairs. This comparison is however, biased toward a decrease in the same way that the 12 study blocks comparison is biased toward an increase.

While variation in numbers of shrikes on individual study blocks was considerable, perhaps due to small sample size, there were no physical changes (land use, habitat, etc.) that seemed to coincide with or 
explain this variation. Potential reasons could include variable effects of weather, predation, prey populations, land management, and factors related to migration and overwintering. Temporary conditions prevalent weeks before census work began may have influenced territory selection.

Because decreasing populations of shrikes are a world-wide phenomenon we suggest that trends on these study blocks be monitored in future.

\section{Acknowledgements}

We thank J. Allen, D. Collister, K. Froggatt, E. Hofman, L. Lester, G. Nieman, I. Pocock and J. Potter, for capable field assistance. D. Collister provided helpful input concerning various aspects of the original study protocol. A. Murphy and two anonymous reviewers provided critical review of earlier drafts. Landowners are thanked for allowing access to their land.

1. BJORGE, RONALD R. and DAVID R.C. PRESCOTT. 1996. Population estimate and habitat associations of the Loggerhead Shrike (Lanius ludovicianus), in southeastern Alberta. Canadian Field-Naturalist 110:445-449.

2. CADMAN, M.D. 1985. Status report on the Loggerhead Shrike (Lanius
Iudovicianus) in Canada. Committee on the Status of Endangered Wildlife in Canada, Ottawa. 86 pp.

3. COLLISTER, D.M. 1994. Breeding ecology and habitat preservation of the Loggerhead Shrike (Lanius Iudovicianus) in southeastern Alberta. Unpublished M.Sc. thesis, University of Calgary. $161 \mathrm{pp}$.

4. JOHNS, B., E. TELFER, M. CADMAN, D. BIRD, R. BJORGE, K. DESMET, W. HARRIS, D. HJERTAS, P. LAPORTE, and R. PITTIWAY. 1994. National recovery plan for the Loggerhead Shrike. Recovery of Nationally Endangered Wildlife Committee Report No. 7. Ottawa. 32 pp.

5. MORRISON, M.L. 1981. Population trends of the Loggerhead Shrike in the United States. American Birds 35: 754-757.

6. PRICE, J., S. DROEGE, and A. PRICE. 1995. The Summer Atlas of North American birds. Academic Press, New York. 364 pp.

7. ROBBINS, C.S., D. BYSTRAK, and P.H. GEISSLER. 1986. The Breeding Bird Survey: its first fifteen years, 1965-1979. United States Fish and Wildlife Service Resource Publication No. 157.196 pp.

8. SEMENCHUK, G.P., 1992. The Atlas of Breeding Birds of Alberta. Federation of Alberta Naturalists, Edmonton.

9. YOSEF, R. and F.E. LOHRER. 1995. Proceedings of the first international shrike symposium. Western Foundation of Vertebrate Zoology 6(1):343 pp.

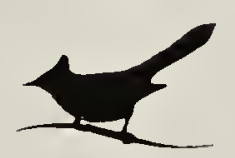

\section{Bird Names}

Franklin, Sir John (1786-1847) British sailor, navigator and Arctic explorer, who died on his fourth Arctic expedition - Franklin's Gull.

Gambel, William (1819-1849) Young naturalist who died of typhoid while exploring and collecting birds - Gambel's Quail.

Harlan, Richard (1796-843) Physician, naturalist, author and friend of Audubon - Harlan's Hawk.

Harris, Edward (1799-1863) A friend, supporter and travelling companion of Audubon - Harris' Hawk and Sparrow. 